\title{
Patch test results in patients with allergic contact dermatitis in the Podlasie region
}

\author{
Teresa Reduta, Joanna Bacharewicz, Anna Pawłoś
}

Department of Dermatology and Venereology, Medical University of Bialystok, Poland Head of Department: Prof. Iwona Flisiak MD, PhD

Postep Derm Alergol 2013; XXX, 6: 350-357

DOI: 10.5114/pdia.2013.39433

\begin{abstract}
Introduction: The aim of the study was to provide current data on the incidence of allergy to various contact allergens in patients with allergic contact eczema and the analysis of selected socio-demographic data of the patients. Material and methods: The study included 1532 patients (1010 women and 522 men) treated for allergic contact dermatitis at the Department of Dermatology and Venereology and at the Dermatology Outpatient Clinic in Bialystok in 2007-2011. The assessment of selected demographic data and skin lesions was based on the MOAHFLA index, while the results of patch tests were analyzed with modified Baseline European Series consisting of 31 allergens. Results: In the group of patients with eczema, $34.1 \%$ were men, and $55 \%$ of all respondents were people over 40 years of age. The occupational character of skin lesions was found in $22.5 \%$. Most frequently (38.9\%) skin lesions were localized on the hands, rarely involved legs (3.98\%). Atopic dermatitis was diagnosed in $4.5 \%$ of patients. The ten most frequent allergens were: nickel sulfate (24\%), cobalt chloride $(15.3 \%)$, fragrance mix (8.25\%), potassium dichromate (6.8\%), balsam of Peru (5.5\%), neomycin (4.42\%), paraphenylenediamine (3.85\%), Quatermium-15 (2.1\%), detreomycin $(1.83 \%)$ and budesonide (1.44\% of tested patients).

Conclusions: Frequent allergy to detreomycin indicates the need of patch testing for this allergen of all examined patients with allergic contact dermatitis. The increased frequency of the nickel allergy is a worrying problem and indicates the need for education about the risk factors for nickel allergy development and the implementation of appropriate legal regulations.
\end{abstract}

Key words: allergic contact dermatitis, MOAHFLA index, patch tests.

\section{Introduction}

Allergic contact dermatitis (ACD) is an inflammatory skin disorder resulting from the skin of allergic persons coming in contact with a small molecular weight chemical compound (hapten). The prevalence of this disease in the general population is evaluated in many countries and ranges from $15 \%$ [1] to $28 \%$ [2] and is increasing [3, 4]. The occurrence of an allergy to specific haptens in a given population depends on the sensitizing potency of the hapten and on the exposure of the skin to this chemical, which involves, inter alia, its prevalence in everyday life and occupational work environment [5].

In the past there were significant differences in the frequency of sensitization to particular allergens between different countries and regions of the world, but now, as a result of the overall process of globalization, gradual disappearance of these differences is observed. This is reflected in the development of a common set of contact allergens for many countries by international bodies. These series of allergens are regularly updated according to the results obtained in different research centers [6-8]. However, literary data indicate a number of variations between different countries, between regions within the same country $[9,10]$ and time variability of the results observed in the same research center [11, 12].

\section{Aim}

The aim of the study was to provide current data on the frequency of sensitization to various contact allergens in patients with allergic contact dermatitis and the analysis of selected socio-demographic and clinical data of the patients.

Address for correspondence: Teresa Reduta MD, PhD, Department of Dermatology and Venereology, Medical University of Bialystok, 14 Żurawia St, 15-540 Bialystok, Poland, phone: +48 85740 95 70, fax: +48 8574094 06, e-mail: treduta@umwb.edu.pl Received: 11.12.2012, accepted: 20.10.2013. 


\section{Material and methods}

The study included 1532 adult patients with suspected allergic contact dermatitis, treated at the Department of Dermatology and Venereology of the Medical University of Bialystok and at the Dermatology Outpatient Clinic of the Regional Specialist Hospital in Bialystok in 2007-2011.

The assessment of selected demographic and clinical data was based on the MOAHFLA (male, occupational dermatitis, atopic dermatitis, hand, face, leg, age > 40) index. The following factors were considered: sex, age, location of primary lesions, occurrence of atopic dermatitis, and the relationship between the development of skin lesions and occupational work. The association of the development of skin lesions with occupational work was established on the basis of a detailed history, clinical picture of skin lesions and patch test results. These data were calculated for the entire study group as well as for men and women separately (Table 1).

Patch tests were set up for $48 \mathrm{~h}$ with a set of 31 allergens, containing an extended standard series of contact allergens which have been used for many years in Poland (F.P. Test Epidermal, E. Jaworski, Katowice, Poland) supplemented by other allergens included in the Baseline Standard Series (Chemotechnique Diagnostics, Sweden) (Table 2). The patch test results were read after $48 \mathrm{~h}$ and $96 \mathrm{~h}$, and were evaluated according to the International Contact Dermatitis Research Group, ICDRG [13].

\section{Results}

The specific demographic and clinical data, taking into consideration the MOAHFLA index, are presented in Table 1. Of the total 1532 ACD patients, 1010 (65.9\%) were women and 522 (34.1\%) were men. The mean age was $43.6 \pm 15.5$ (range: $18-88$ ) years, the proportion of patients above 40 years of age was $55 \%$ of all patients. The occupational character of skin lesions was found in 246 people $(22.5 \%)$, with a similar incidence in both sexes, 188 women (12.2\%) and 158 men (10.3\%). The most frequent localization (seen in 596 (38.9\%) patients) of the eczematous lesions were hands. Facial eczema was detected in 185 (12.07\%) patients. Rarely (in 61 (3.98\%) patients) eczematous lesions were observed on legs. Facial eczema affected 151 (9.86\%) women and 34 (2.21\%) men, hand eczema was found in 371 women (24.2\%) and 225 men (14.7\%). However, leg dermatitis was detected in 33 (2.15\%) women and 28 (1.83\%) men. Atopic dermatitis was found in 69 (4.5\%) patients. Positive patch test results with at least one allergen were obtained for 828 (54\%) patients, more frequently in men than in women (60.1\% vs. $42.3 \%)$. The frequency of sensitization to allergens used for the study is shown in Table 3. Positive reactions were observed most commonly for nickel sulfate $(24 \%)$, cobalt chloride (15.3\%), fragrance mix (8.25\%), potassium dichromate (6.8\%), balsam of Peru $(5.5 \%)$, neomycin sulfate (4.42\%), p-Phenylenediamine (3.85\%). Less common were: Quatermium-15 (2.1\%), detreomycine $(1.83 \%)$, budesonide (1.44\%), colophonium (1.4\%), tixocortol pivalate (1.37\%), 4-tert-butylphenol formaldehyde resin (1.3\%), thiuram (1.24\%), benzocaine/caine mix (1.12\%). An allergy to: paraben mix (0.84\%), mercaptobenzothiazole $(0.72 \%)$, primin $(0.7 \%)$, N-isopropyl-N'-phenyl-p-phenylenediamine $(0.65 \%)$, rivanol (0.54\%), epoxy resin $(0.46 \%)$, formaldehyde $(0.4 \%)$, mercury chloride

Table 1. Demographic and clinical data of patients with allergic contact dermatitis considering the MOAHFLA index

\begin{tabular}{|c|c|c|c|c|c|c|}
\hline \multirow{2}{*}{ Gender } & \multicolumn{2}{|c|}{ Females } & \multicolumn{2}{|c|}{ Males } & \multicolumn{2}{|c|}{ Total } \\
\hline & $n$ & $\%$ & $n$ & $\%$ & $n$ & $\%$ \\
\hline $\mathbf{M}($ ale $)$ & 1010 & 65.9 & 522 & 34.1 & 1532 & \\
\hline O(ccupational) & 188 & 18.65 & 158 & 30.3 & 346 & 22.5 \\
\hline A(topic dermatitis) & 53 & 5.2 & 17 & 3.3 & 69 & 4.5 \\
\hline $\mathrm{H}$ (and) & 371 & 36.7 & 225 & 43.1 & 596 & 38.9 \\
\hline F(ace) & 151 & 14.95 & 34 & 6.5 & 185 & 12.07 \\
\hline L(eg) & 33 & 3.3 & 28 & 5.4 & 61 & 3.98 \\
\hline \multicolumn{7}{|l|}{ A(ge) [years] } \\
\hline Mean & $42.7 \pm 15.02$ & & $45.5 \pm 15.9$ & & $43.6 \pm 15.5$ & \\
\hline Range & (18-88) & & $(18-85)$ & & $(18-88)$ & \\
\hline$>40$ & 542 & 53.7 & 301 & 57.7 & 843 & 55.02 \\
\hline Positive results & 607 & 60.1 & 221 & 42.3 & 828 & 54.04 \\
\hline
\end{tabular}

$n$ - number of tested patients 
Table 2. The series of allergens used for patch testing

\begin{tabular}{|c|c|c|c|}
\hline No. & Substance & Concentration & Vehicle \\
\hline 1 & Nickel sulfate ${ }^{1}$ & 5 & Petrolatum \\
\hline 2 & Cobalt chloride ${ }^{1}$ & 1 & Petrolatum \\
\hline 3 & Potassium dichromate $^{1}$ & 0.5 & Petrolatum \\
\hline 4 & Mercury chloride ${ }^{1}$ & 0.03 & Water \\
\hline 5 & Neomycin sulfate ${ }^{1}$ & 20 & Petrolatum \\
\hline 6 & Fragrance $\mathrm{mix}^{2}$ & 8 & Petrolatum \\
\hline 7 & Balsam of Peru ${ }^{1}$ & 25 & Petrolatum \\
\hline 8 & Thiuram ${ }^{1}$ & 1 & Petrolatum \\
\hline 9 & Colophonium ${ }^{1}$ & 20 & Petrolatum \\
\hline 10 & p-Phenylenediamine $(\mathrm{PFD})^{1}$ & 1 & Petrolatum \\
\hline 11 & $\mathrm{~N}$-isopropyl-N'-phenyl-p-phenylenediamine (IPPD) ${ }^{1}$ & 0.15 & Petrolatum \\
\hline 12 & Paraben mix ${ }^{1}$ & 9 & Petrolatum \\
\hline 13 & Methyldibromoglutaronitrile (MBGN) $)^{2}$ & 0.5 & Petrolatum \\
\hline 14 & Benzocaine/caine $\mathrm{mix}^{2}$ & 5 & Petrolatum \\
\hline 15 & Sesquiterpene lactone mix, Lactone $\mathrm{mix}^{2}$ & 0.1 & Petrolatum \\
\hline 16 & Budesonide $^{2}$ & 0.01 & Petrolatum \\
\hline 17 & Lanolin alcohol ${ }^{1}$ & 30 & Petrolatum \\
\hline 18 & Detreomycin ${ }^{1}$ & 2 & Petrolatum \\
\hline 19 & Epoxy resin ${ }^{1}$ & 1 & Petrolatum \\
\hline 20 & 4-tert-butylphenol formaldehyde resin ${ }^{2}$ & 1 & Petrolatum \\
\hline 21 & Mercaptobenzothiazole ${ }^{1}$ & 2 & Petrolatum \\
\hline 22 & Quatermium-15² & 1 & Petrolatum \\
\hline 23 & Salicylic acid ${ }^{3}$ & 5 & Petrolatum \\
\hline 24 & Rivanol $^{3}$ & 1 & Petrolatum \\
\hline 25 & 2-metoksy-6-n-pentylo-4-benzochinon, Primin ${ }^{2}$ & 0.01 & Petrolatum \\
\hline 26 & Methylchloroisothiazolinone/Methylisothiazolinone (MCI/MI), Kathon $\mathrm{CG}^{2}$ & 0.01 & Water \\
\hline 27 & Tixocortol-21-pivalate ${ }^{2}$ & 0.1 & Petrolatum \\
\hline 28 & Clioquinol $^{2}$ & 5 & Petrolatum \\
\hline 29 & Hydroxyizohexyl-3-cyclohexene-carboxaldehyde, Lyral ${ }^{2}$ & 5 & Petrolatum \\
\hline 30 & Turpentine $^{1}$ & 10 & Rapeseed oil \\
\hline 31 & Formaldehyde $^{1}$ & 0.7 & Water \\
\hline
\end{tabular}

${ }^{1}$ F.P Testów naskórkowych, E. Jaworski, Katowice, Poland, ${ }^{2}$ Chemotechnique Diagnostics, Sweden, ${ }^{3}$ additional allergens

(0.4\%), methyldibromo glutaronitrile (0.36\%), turpentine (0.32\%), methylchloroisothiazolinone/methylisothiazolinone $(0.32 \%)$, lactone mix $(0.32 \%)$, clioquinol $(0.27 \%)$ and salicylic acid (0.26\%) was rarely detected.

\section{Discussion}

The analysis of the demographic data of examined eczema patients in Bialystok showed strong similarities in terms of age and sex to the population of patients 
Table 3. Positive patch test results with contact allergens in patients with allergic contact dermatitis

\begin{tabular}{|c|c|c|c|c|c|c|}
\hline \multirow[b]{2}{*}{ No. } & \multirow[b]{2}{*}{ Allergen } & \multirow{2}{*}{$\begin{array}{c}\text { Number of tested } \\
\text { patients } \\
\text { (female/male) }\end{array}$} & \multicolumn{3}{|c|}{ Number of positive results } & \multirow[b]{2}{*}{ Value of $p$} \\
\hline & & & $\begin{array}{l}\text { Total } \\
n(\%)\end{array}$ & $\begin{array}{l}\text { Female } \\
n(\%)\end{array}$ & $\begin{array}{l}\text { Male } \\
n(\%)\end{array}$ & \\
\hline 1 & Nickel sulfate & $1532(1010 / 522)$ & $368(24)$ & $334(33.1)$ & $34(6.51)$ & $<0.0001^{\#}$ \\
\hline 2 & Cobalt chloride & $1532(1010 / 522)$ & $240(15.3)$ & $186(18.4)$ & $54(10.3)$ & $<0.001^{\#}$ \\
\hline 3 & Fragrance mix & $1532(1010 / 522)$ & $125(8.3)$ & $86(8.5)$ & $39(7.5)$ & 0.49 \\
\hline 4 & Potassium dichromate & $1532(1010 / 522)$ & $105(6.8)$ & $62(6.1)$ & $43(8.2)$ & 0.12 \\
\hline 5 & Balsam of Peru & $1532(1010 / 522)$ & $85(5.5)$ & $58(5.7)$ & $27(5.1)$ & 0.4 \\
\hline 6 & Neomycin sulfate & $1532(1010 / 522)$ & $69(4.42)$ & $38(3.7)$ & $31(5.9)$ & $<0.05^{\#}$ \\
\hline 7 & PFD & $1532(1010 / 522)$ & $59(3.85)$ & $41(4.1)$ & $18(3.4)$ & 0.5 \\
\hline 8 & Quatermium-15 & $713(468 / 245)$ & $15(2.1)$ & $11(2.35)$ & $4(1.6)$ & 0.5 \\
\hline 9 & Detreomycin & $1532(1010 / 522)$ & $28(1.83)$ & $14(1.4)$ & $10(1.9)$ & 0.45 \\
\hline 10 & Budesonide & $1532(1010 / 522)$ & $22(1.44)$ & $12(1.2)$ & $10(1.9)$ & 0.27 \\
\hline 11 & Colophonium & $1532(1010 / 522)$ & $22(1.4)$ & $18(1.8)$ & $4(0.77)$ & $<0.01^{\#}$ \\
\hline 12 & Tixocortol-21-pivalate & $267(160 / 107)$ & $4(1.37)$ & $1(0.6)$ & $3(2.8)$ & 0.22 \\
\hline 13 & $\begin{array}{l}\text { 4-tert-butylphenol formalde- } \\
\text { hyde resin }\end{array}$ & $1251(815 / 436)$ & $16(1.3)$ & $6(0.7)$ & $10(2.3)$ & $<0.05^{\#}$ \\
\hline 14 & Thiuram & $1532(1010 / 522)$ & $19(1.24)$ & $9(0.9)$ & $10(1.9)$ & $<0.001^{\#}$ \\
\hline 15 & Benzocaine/Caine mix & $1110(716 / 394)$ & $17(1.12)$ & $12(1.7)$ & $5(1.3)$ & 0.54 \\
\hline 16 & Lanolin alcohol & $1532(1010 / 522)$ & $14(0.91)$ & $8(0.8)$ & $6(1.15)$ & 0.49 \\
\hline 17 & Paraben mix & $1532(1010 / 522)$ & $13(0.84)$ & $12(1.2)$ & $1(0.1)$ & $<0.05^{\#}$ \\
\hline 18 & Mercaptobenzothiazole & $1532(1010 / 522)$ & $11(0.72)$ & $4(0.4)$ & $7(1.34)$ & $<0.05^{\#}$ \\
\hline 19 & Primin & $291(174 / 117)$ & $2(0.7)$ & $2(1.15)$ & 0 & 0.24 \\
\hline 20 & IPPD & $1532(1010 / 522)$ & $10(0.65)$ & $6(0.6)$ & $4(0.77)$ & 0.69 \\
\hline 21 & Rivanol & $1532(1010 / 522)$ & $7(0.54)$ & $5(0.49)$ & $2(0.13)$ & 0.2 \\
\hline 22 & Epoxy resin & $1532(1010 / 522)$ & $7(0.46)$ & $4(0.4)$ & $3(0.6)$ & 0.58 \\
\hline 23 & Mercury chloride & $1532(1010 / 522)$ & $6(0.4)$ & $3(0.3)$ & $3(0.6)$ & 0.78 \\
\hline 24 & Formaldehyde & $1532(1010 / 522)$ & $6(0.4)$ & $4(0.4)$ & $2(0.13)$ & 0.36 \\
\hline 25 & Methyldibromo glutaronitrile & $1110(716 / 394)$ & $4(0.36)$ & $2(0.3)$ & $2(0.4)$ & 0.78 \\
\hline 26 & Lactone mix & $1532(1010 / 522)$ & $5(0.32)$ & $4(0.4)$ & $1(0.1)$ & 0.3 \\
\hline 27 & $\mathrm{CMI} / \mathrm{MI}$ & $1532(1010 / 522)$ & $5(0.32)$ & $5(0.5)$ & 0 & 0.1 \\
\hline 28 & Turpentine & $1532(1010 / 522)$ & $5(0.32)$ & $5(0.5)$ & 0 & 0.1 \\
\hline 29 & Clioquinol & $1487(979 / 508)$ & $4(0.27)$ & $3(0.3)$ & $1(0.2)$ & 0.72 \\
\hline 30 & Lyral & $1532(1010 / 522)$ & $4(0.27)$ & $1(0.1)$ & $3(0.57)$ & $<0.001^{\#}$ \\
\hline 31 & Salicylic acid & $1532(1010 / 522)$ & $4(0.26)$ & $2(0.2)$ & $2(0.38)$ & 0.5 \\
\hline
\end{tabular}

\#Statistically significant, $p<0.05$ 
with eczema evaluated in other countries. As in most other countries, we observed almost double the number of women among eczema patients (percentage of men 34.1\%). Fifty-five percent of people examined were above 40 years old, which was similar to other groups of eczema patients $[9,10,14]$.

Among the patients of the clinic in Bialystok, the occupational character of skin lesions was observed in $22.5 \%$ of people, significantly more often in men. Based on the available literary data, the occupational nature of allergic contact dermatitis has been reported in a wide range: from $4.1 \%$ to $55 \%$, depending on the health center, more often in centers specializing in occupational diseases, where patients with a specific profile register [9, 15].

Atopic dermatitis was observed in $4.5 \%$ of patients with contact dermatitis. The percentage is lower in comparison with results from other countries, where the atopic dermatitis was seen in $6.9 \%$ to $37 \%$ of respondents. The explanation for these differences may be that in our study we included only adults, in contrast to other centers, where children were also evaluated. Another reason may be a lower incidence of atopic dermatitis in Poland [16].

The most common primary location of eczematous lesions was the hands (38.9\%). Hand eczema prevailed among men. The percentage of patients with hand dermatitis was similar to that in other countries [9] but lower than in the occupational disease centers in Finland and Poland $[9,15]$. The second most common location of lesions was the face ( $12.1 \%$ of patients), more than twice as often in women than men (14.95\% vs. 6.5\%). Surprising is the small percentage of patients with leg eczema (3.98\%), since in this group contact allergy is developed by most patients. The explanation of this may be the rarity of patients with leg ulcers being hospitalized by our department, which means that these patients are not diagnosed for contact allergy. In other European countries, patients with leg eczema were observed with various frequency varying from $3.3 \%$ in the UK to $17.5 \%$ in Denmark, and only $1.4 \%$ of the tested patients with eczema at the Centre of Occupational Diseases in Finland.

The frequency of positive patch test results in the patients (54\%) as well as a clear predominance of women among applicants with eczema, are within the range of results available in the literature, domestic and foreign $[2,9,15]$.

Most positive patch tests in the study group were obtained for nickel sulfate ( $24 \%$ of the tested). This value is similar to the results from the Institute of Occupational Medicine in Lodz [15] and most European countries [9], with the exception of Denmark, Germany and Sweden, where a significant decrease in allergy to this metal has been observed in recent years [17-21]. In 1990, Denmark introduced a legal regulation limiting the concentration of nickel in objects which come in direct contact with the skin [22], and in 2001, the so-called European Nickel Directive legislation was introduced all across the Euro- pean Union [23]. Compared with previous studies, the percentage of people allergic to nickel has increased in our center over the last 10 years (from 17\%) [24], despite the "nickel directive" - in force since 2005. An increase in allergies to nickel has recently been observed in the United States and other countries where there are no regulations limiting exposure to the metal $[25,26]$. Allergy to nickel is observed significantly more often among women (visible in our patients), which is explained by early exposure to allergens contained in jewelry, especially earrings.

The second most frequent allergen detected among patients was cobalt chloride. Positive reactions to this allergen occurred in $15.3 \%$ of people tested, and this percentage was greater than in other European countries [9]. Most patients with positive cobalt tests also had allergies to nickel and chromium, and it was significantly more frequent, especially in the case of nickel, among women. Fragrances evoked positive reactions in $8.25 \%$ of patients, ranking the third. This is similar in proportion to the results found in many other European countries, but higher than the results from Spain (3.8\%) and lower than in Germany (12.4\%), the Netherlands (12.8\%), Belgium (11.2\%) and Denmark (11\%) [14, 27]. When compared with a period of 10 years ago in Bialystok, there has been a slight increase in allergies to fragrances, which seems to reflect a general trend [27]. Positive test results occurred slightly more often among women, but the difference was not statistically significant. The sources of allergies to fragrances are mostly cosmetics but the allergy may also develop through occupational conditions.

Balsam of Peru has been an important contact allergen since the first set of allergens was developed in 1969. It is considered an indicator of allergies to fragrances, detecting about $50 \%$ of allergies to this group of allergens $[28,29]$.

Among our patients positive patch tests with balsam of Peru were found in $5.5 \%$ of patients. Balsam is a substance which is derived from the Myroxolon balsamum tree, contains a number of allergenic compounds that are added to food fragrances and flavorings, which also cause cross-reactions with many products of plant origin, such as colophony, turpentine and wood tar.

Positive test results to potassium dichromate were found in $6.8 \%$ of patients and were similar to those observed 10 years ago. This is a slightly lower percentage compared with the results of the Nofer Institute in Lodz (9.5\%), but similar to those observed in Sweden and Portugal [14]. A surprising phenomenon was that no significant difference in the occurrence of positive results for chromium was observed among our patients between men and women. Until now, the allergy to chromium concerned mainly men and often had an occupational character, which in the past was also observed in the Bialystok clinic. Currently, the source of this allergy has become contact with leather items [30], 
which may to some extent explain the change observed in the sex ratio.

Neomycin held a high position $(4.4 \%$ of positive reactions) among the most common contact allergens in the patients examined, however the percentage of positive results for this allergen has decreased by half in our center over the past 10 years. The reason for this decline is probably a significantly lower representation of patients with leg ulcers among whom the allergy to neomycin is particularly common and which affects about one third of patients [29, 31]. It is also assumed that the high prevalence of sensitization caused less frequent use of the antibiotic by dermatologists. The percentage of patients who are allergic to neomycin in the entire study group is slightly higher compared to the data from most other European countries, with the exception of Finland, where positive tests with this antibiotic are observed in up to $7.7 \%$ of tested patients [14]. Significantly more positive results with neomycin were reported among men.

In our group of ACD patients $p$-phenylenediamine was the cause of positive reactions in $3.85 \%$, which is in the range of results from other studies in Poland and abroad [14, 15]. Previous studies in Bialystok showed that the allergy to PFD was found significantly more often among women, but currently this difference does not show signs of significance. Paraphenylenediamine is the aromatic amine present in commonly used hair and clothing dyes and in pigments for tattoos. The fashion for hair coloring in young women and girls, as well as the popularity of temporary and permanent tattoos have resulted in a significant increase in the allergy to this substance. Paraphenylenediamine is a potent contact allergen that can also cause very serious allergic reactions of immediate type [32] and in rare cases, the intravascular hemolysis leading to renal failure [33]. The allergy to PFD is also clinically important due to the possibility of cross reactions with many other substances from the so-called para group such as: pigments of many hair and clothing dyes, components of rubber, epoxy resins, local anesthetics and sulfonamides. The positive phenomenon seen in our ACD patients is the almost twofold decrease in the frequency of positive patch test results for PFD over the past 10 years. This is probably caused by the decreased content of this substance in hair dyes.

Positive tests for Quatermium-15 occurred in 2.1\% of ACD patients which placed this allergen in the ninth position on the list of allergens. In other European countries the percentage of positive results for this allergen varies between $0.7 \%$ and $2.7 \%$ [14]. Quatermium-15, or Dowicil 200 , is the most frequently sensitizing substance among formaldehyde-releasing preservatives included in many cosmetics, hygiene care products and cleaning agents, but the allergy may also develop through occupational conditions [34].

Positive reactions to Quatermium-15 are accompanied by more than $50 \%$ of reactions to formaldehyde
[35], but in our patients, the percentage was lower, which probably depended on the lower concentration used as the patch testing substance.

Ten most frequent allergens in patients tested in our department included also detreomycin, giving positive patch test reactions in $1.83 \%$ of patients examined, with equal frequency in women and in men. This percentage is similar to the results of a former study performed in $\mathrm{Bi}$ alystok [24]. Detreomycin is not included in the European baseline standard series, but is used in the treatment of skin diseases both in humans and animals. It is for this reason that we still routinely perform patch tests with this allergen.

An allergy to budesonide occurred in $1.44 \%$ of patients and slightly less frequently to tixocortol-21-pivalate (1.37\% of patients tested). Together, both corticosteroids caused positive reactions in $2.81 \%$ of ACD patients, which makes them an important group of contact allergens. The percentage of reactions to budesonide is within the range of results obtained in other European centers, varying from $0.1 \%$ to $2.3 \%$ of tested patients, similarly to reactions to tixocortol-21-pivalate which varies from $0.7 \%$ to $3 \%$ [14]. Less frequent (0.7\%) allergy to both corticosteroids was noted in Sweden (Malmo), while the most frequent (6.2\%) positive reactions were obtained in Germany (Dortmund) [14]. Reaction to budesonide is a good marker for the detection of an allergy to many topical fluorinated corticosteroids from group $\mathrm{B}$, whereas tixocortol-21-pivalate detects hypersensitivity to hydrocortisone derivates from group A according to Coopman's classification [36]. Corticosteroids included in this patch test series may also detect an allergy to substances from group D due to the possibility of cross reactions.

Quite frequently (above 1\% of those tested) positive results were obtained for colophony, formaldehyde, resins, thiuram and benzocaine. An allergy to colophony $(1.4 \%)$ is at present seen in our department less frequently than 10 years ago (3.8\%) and also in other European countries, where it varies between $1.9 \%$ and 5.2\% [14].

Formaldehyde resins caused positive reactions in $1.3 \%$ of ACD patients, which was similar to those in Belgium (1.4\%) and Germany (1.5\%) but less frequent than in Spain (3\%), Finland (4.3\%) and Denmark (3.2\%) $[10,14]$. An allergy to thiuram currently affects $1.4 \%$ of the contact eczema patients in our department, which is comparable with results from Sweden. In the past, hypersensitivity to thiuram was twice as frequent and similar to data from most other European centers. Very similar test results were obtained with benzocaine. Positive reactions to this allergen were seen slightly less frequently than in other countries and than in our department 10 years ago [24].

Comparing our results to the data from the Nofer Institute in Lodz, similar frequency of positive reactions was obtained with nickel sulfate, cobalt chloride and Balsam of Peru. Formaldehyde, turpentine, benzocaine, thi- 
uram and mercaptobenzothiazole included in the list of the ten most frequent allergens in Lodz were not present in our results. Instead, we observed fragrances, neomycin, detreomycin, budesonide and Quatermium-15. The explanation to these differences may be that the majority of patients in Lodz had occupational contact eczema, whereas in Bialystok all ACD patients were examined.

Our patients showed a low incidence of hypersensitivity to preservatives included in a series of allergens used for testing: clioquinol, methylobromoglutaronitrile, Kathon CG and formaldehyde. These results are very similar to the data from Spain [10]. The exception in our patients was the Quatermium-15 and paraben mix, which caused positive patch test reactions in more than $1 \%$ of tested patients, similarly to the results from Germany. In other European countries, the frequency of allergy to these 2 substances was lower, but it was higher for the remaining preservatives $[14,37,38]$.

Few positive reactions (0.32\%) were noticed with sesquiterpene lactones, the only plant allergen used in the series of tested substances. Reactions to this allergen concerned almost entirely farmers (data not shown). Higher percentages were seen in other regions of Europe [9]. Allergy to methylobromodiglutaronitrile varied within a broad range: from 0-0.3\% in Southern Europe to 5.6\% in Central Europe [9].

The current patch test results for consecutive adult patients with allergic contact dermatitis have been presented. The proportion of women and men, as well as the distribution of the age groups, are similar to most of those observed in analogous eczema patients groups from other European countries. However, remarkable differences have been noticed in the other characteristics from the MOAHFLA index: incidence of atopic dermatitis, occupational character of eczema and localization of skin lesions.

Unlike in other European countries, among 10 most frequently sensitizing allergens some were not present in patients examined in Bialystok, such as: thiuram, formaldehyde and most of frequently used preservatives. Detreomycin, which is not included in the baseline series of allergens, was, however, still present. The high incidence of hypersensitivity indicates the need for testing of all eczema patients for this antibiotic.

The decline of allergy to neomycin, paraphenylenediamine, thiuram is beneficial. The increase in the frequency of the allergy to nickel is a worrying problem, which indicates the need for education about the risk factors for nickel allergy development and for the implementation of the appropriate legal regulations.

\section{References}

1. Tyssen JP, Linnenberg A, Menne T, Johansen JD. The epidemiology of contact allergy in the general population - prevalence and main findings. Contact Dermatitis 2007; 57: 287-9.
2. Schäfer T, Böhler E, Ruhdorfer S, et al. Epidemiology of contact allergy. Allergy 2001; 56: 1192-6.

3. Asher MI, Montefort S, Bjorksten B, et al. Worldwide time trends in the prevalence of symptoms of asthma, allergic rhinoconjunctivitis, and eczema in childhood: ISAAC Phases One and Three repeat multicountry cross-sectional surveys. Lancet 2006; 368: 733-43.

4. Czarnobilska E, Obtulowicz K, Dyga W, Spiewak R. A half of schoolchildren with "ISAAC eczema" are ill with allergic contact dermatitis. J Eur Acad Dermatol Venereol 2011; 25: 1021-6.

5. Jenerowicz D, Silny W, Dańczak-Pazdrowska A, et al. Environmental factors and allergic diseases. Ann Agric Environ Med 2012; 19: 475-48.

6. Uter W, Hegewald J, Aberer W, et al. The European standard series in 9 European countries 2002/2003 - first results of the European Surveillance System on Contact Allergies. Contact Dermatitis 2005; 53: 136-45.

7. Żukiewicz-Sobczak W, Adamczuk P, Wróblewska P, et al. Allergy to selected cosmetic ingredients. Postep Derm Alergol 2013; 30: 307-10

8. Silny W, Bartoszak L, Jenerowicz D, et al. Prevalence of contact allergy in children suffering from atopic dermatitis, seborrhoeic dermatitis and in healthy controls. Ann Agric Environ Med 2013; 20: 55-60.

9. Uter W, Ramsch C, Aberer W, et al. The European baseline series In 10 European Countries, 2005/2006 - results of the European Surveillance System on Contact Allergies (ESSCA). Contact Dermatitis 2009; 61: 31-8.

10. Aguilar-Bernier M, Bernal-Riuz Al, Rivaz-Ruiz F, et al. Contact sensitization to allergens in the Spanish Standard Series at Hospital Costa del Sol in Marbella, Spain: a retrospective study (2005-2010). Actas Dermosifiliogr 2012; 103: 223-38.

11. Rudzki E. Changes in the pattern of sensitization [Polish]. Alergia Astma Immunologia Kliniczna 2005; 2: 53-7.

12. Nguyen SH, Dang TP, MacPherson C, et al. Prevalence of patch test results from 1970 to 2002 in a multi-centre population in North America (NACDG). Contact Dermatitis 2008; 58: 101-6.

13. Lachapelle JM, Maibach HI. Patch testing. Prick testing. Springer, Berlin 2003; 27-69.

14. Bruynzeel DP, Diepgen TL, Andersen KE, et al. Monitoring the European standard series in 10 centres 1996-2000. Contact Dermatitis 2005; 53: 146-52.

15. Kieć-Świerczyńska M, Kręcisz B, Chomiczewska D, et al. Trends In allergy to the 10 most frequent contact allergens in patients examined at Nofer Institute, Lodz, Poland in 1996-2009. Postep Derm Alergol 2012; 29: 19-24.

16. Małolepszy J. Występowanie chorób alergicznych w Polsce. [Polish]. Alergia Astma Immunologia 2000; S2: 163-9.

17. Jensen CS, Lisby S, Baadsgaard O, et al. Decrease in nickel sensitization in a Danish schoolgirl population with ears pierced after implementation of a nickel-exposure regulation. Br J Dermatol 2002; 146: 636-42.

18. Schnuch A, Uter W. Decrease in nickel allergy in Germany and regulatory interventions. Contact Dermatitis 2003; 49: 107-8.

19. Lindberg M, Edman B, Fischer T, Stenberg B. Time trends in Swedish patch test data from 1992 to 2000. A multicentre study based on age- and sex-adjusted results of the Swedish standard series. Contact Dermatitis 2007; 56: 205-10.

20. Liden C, Norberg K. Nickel on the Swedish market. Follow-up after implementation of the Nickel Directive. Contact Dermatitis 2005; 52: 29-35. 
21. Limańska M, Żmudzińska M, Jenerowicz D, et al. The importance of exposure to contact allergens in patients with allergic contact dermatitis. Post Dermatol Alergol 2011; 28: 203-11.

22. Menne T, Rasmussen K. Regulation of nickel exposure in Denmark. Contact Dermatitis 1990; 23: 57-8.

23. European Parliament and Council Directive 94/27/EC of 30 June 1994 amending for the 12th time Directive 76/769/EEC on the approximation of the laws, regulations and administrative provisions of the Member States relating to restrictions on the marketing and use of certain dangerous substances and preparations. Official Journal L 1994; 188: 1-2.

24. Reduta T, Laudańska H, Chodynicka B. Contact hypersensitivity in patients of the Department of Dermatology and Venereology during the last five years [Polish]. Przegl Dermatol 2002; 3: 193-7.

25. Rietschel RL, Fowler JF, Warshaw EM, et al. Detection of nickel sensitivity has increased in north American patch-test patients. Dermatitis 2008; 19: 16-9.

26. Teh-Yang C, Yu-Hsian T, Chee-Ching S, Chia-Yu C. Contact sensitization to metals in Taiwan. Contact Dermatitis 2008; 59: 353-60.

27. Lunder T, Kansky A. Increase in contact allergy to fragrances: patch-test results 1989-1998. Contact Dermatitis 2000; 43: 107-9.

28. Kohl L, Blondeel A, Song M. Allergic contact dermatitis from cosmetics. Retrospective analysis of 819 patch-tested patients. Dermatology 2002; 204: 334-7.

29. Rudzki E, Rebandel P, Parapura K. Allergens of stasis dermatitis [Polish]. Przegl Dermatol 2004; 91: 107-30.

30. Tyssen JP, Hald M, Avnstorp C, et al. Characteristics of nickel-allergic dermatitis patients seen in private dermatology clinics in Denmark: a questionnaire study. Acta Derm Venereol 2009; 89: 384-8.

31. Reduta T, Laudańska H, Chodynicka B. Contact allergy in patients with eczema cruris and leg ulcers [Polish]. Przegl Dermatol 2001; 88: 157-60.

32. Sosted H, Agner T, Andersen KE, et al. 55 cases of allergic reactions to hair dye: a descriptive, consumer complaint-based study. Contact Dermatitis 2002; 47: 299-303.

33. Anuradha S, Arora S, Mehrotra S, et al. Acute renal failure following para-phenylenediamine (PPD) poisoning: a case report and review. Renal Failure 2004; 26: 329-32.

34. Jong CT, Statham BN, Green CM. Contact sensitivity to preservatives in the UK, 2004-2005, results of multicentre study. Contact Dermatitis 2007; 57: 165-8.

35. De Groot A, Blok J, Coenraads PJ. Relationship between formaldehyde and quatermium-15 contact allergy. Influence of strength of patch test reactions. Contact Dermatitis 2010; 63: 187-91.

36. Coopman S, Degret H, Dooms-Goossens A. Identification of cross-reaction patterns in allergic contact dermatitis from topical corticosteroids. Br J Dermatol 1989; 121: 27-34.

37. Reinhard E, Waeber R, Niederer M, et al. Preservation of products with $\mathrm{MCl} / \mathrm{MI}$ in Switzerland. Contact Dermatitis 2001; 45: 257-64.

38. Wilkinson JD, Shaw S, Andersen KE, et al. Monitoring levels of preservative sensitivity in Europe. Contact Dermatitis 2002; 46: 207-10. 